\title{
Performance of the Savonius Wind Rotor with Two Inner Blades at Low Tip Speed Ratio
}

\author{
Mohanad Al-Ghriybah ${ }^{1,3,}{ }^{*}$, Mohd Fadhli Zulkafli ${ }^{1}$, Djamal Hissein Didane ${ }^{2}$, Sofian Mohd ${ }^{1}$ \\ 1 Department of Aeronautical Engineering, Faculty of Mechanical and Manufacturing Engineering, Universiti Tun Hussein Onn Malaysia (UTHM), \\ Johor, Malaysia \\ 2 Department of Energy and Thermofluid Engineering, Faculty of Mechanical and Manufacturing Engineering, Universiti Tun Hussein Onn \\ Malaysia (UTHM), Johor, Malaysia \\ Department of Renewable Energy Engineering, Faculty of Engineering, Al-Isra University, Amman, Jordan
}

\section{ARTICLE INFO}

\section{Article history:}

Received 22 January 2020

Received in revised form 17 March 2020

Accepted 22 March 2020

Available online 28 March 2020

\section{Keywords:}

Savonius rotor; Inner blades; wind turbines; VAWT

\section{ABSTRACT}

The Savonius wind turbine is considered as one of the solutions for harvesting the kinetic energy from the wind in the urban areas, due to magnificent features such as, low construction cost, high starting torque, and self-starting ability especially at low wind speed. However, the conventional rotor suffers from low efficiency. Thus, modifying the configuration of the rotor may be an effective solution for providing electricity to the communities with no access to the power grid. Thus, this investigation aims to study numerically the effect of adding two inner blades on the performance of the Savonius wind rotor at low tip speed ratios (TSRs). The simulations are carried out using the two-dimensional simulation with the assist of ANSYS software. For turbulence modelling, the $\mathrm{K}-\varepsilon /$ realizable model was adopted in this study. Power coefficient $\left(C_{p}\right)$ and torque coefficient $\left(C_{t}\right)$ at various TSRs for the rotor are determined under a constant external overlap of $0.018 \mathrm{~m}$. Furthermore, the effect of space between the inner blades was also investigated using three values of spacing. The simulation results show that the rotor with two inner blades performs better than the same rotor without inner blades at all tested TSRs expect at low considered values of 0.2 and 0.25 . The heights $\mathrm{Cp}$ was 0.188 with $17.1 \%$ performance improvement at TSR $=0.4$. Furthermore, the numerical results show that $C_{p}$ values decrease with the decrease of the space between the blades.

Copyright $@ 2020$ PENERBIT AKADEMIA BARU - All rights reserved

\section{Introduction}

Utilizing renewable energy has become very significant to the industries and the governments over the world as a result of the air pollution generated from burning conventional fossil fuels [1]. Wind energy is one of the most promising alternatives as it a clean source of energy and available in wide ranges. Albeit the utilize of wind power technologies has prevailed developing very expeditiously, the generated electricity from wind power still much less than the derived electricity

\footnotetext{
* Corresponding author.

E-mail address: Mohanad.alghriybah@gmail.com (Mohanad Al-Ghriybah)
} 
from the fossil fuel based power plants [2]. However, Wind power has become a paramount segment of the yearly energy consumption portfolios of many countries around the world [3].

Recently, the investigations on the Vertical Axis Wind Turbines (VAWTs) from researchers have increased due to the unique features of VAWTs such as simplicity, independent from wind direction and lower in cost [4-8]. Whereas the Horizontal Axis Wind Turbines (HAWT) have gained the main segment in the wind energy market, the VAWT technology is expected to play a key role in the near decades [9].

Generally, the main drawback of the VAWT is the low efficiency compared to the HAWT, which requires more research on its aerodynamics in order to improve its performance characteristics [10]. This type of wind machines can be categorized into two main configurations i.e. Savonius (S-rotor) and Darrieus rotor [11]. The Darrieus type is a lift-based rotor which consists of multi-curved blades whereas the Savonius type relies more on the drag force and it usually consists of two semi-cylindrical blades. Although the Darrieus rotor has higher efficiency and can generate higher power, Savonius rotors have better starting performance than the other VAWTs [12]. Moreover, the Savonius rotor offers significant features such as the self-starting ability, low maintenance costs, simple construction and high starting torque [13]. Since the main design parameters of the Savonius rotor are the aspect ratio, overlap ratio, number of stages, number of blades and blade's profile, numerous studies have been conducted on those parameters in order to enhance the performance of the turbine.

Many experimental studies on the Savonius rotor are done. These studies also include modified designed rotors. Mahmoud et al., [14] conducted parametric investigations on the influences of end plates, aspect ratio, number of blades, number of stages, and overlap ratio. They concluded that end plates and double stage rotor enhance the turbine efficiency, whereas the overlap and multi blades decrease the turbine performance. Bhayo et al., [15] tested a modified conventional Savonius rotor with two and three blades in an open wind tunnel simulator. The maximum power coefficient is obtained to be about ( $C_{p}=26 \%$ ). Roy and Saha [16] examined a newly developed Savonius rotor with a different type of blades taking into consideration the effect of wind tunnel blockage. They achieved a maximum $C_{p}$ of $34.8 \%$. Kemoji et al., [17] proposed a helical Savonius rotor and they tested it in an open jet wind tunnel. They reached a maximum coefficient of power of about $17.4 \%$. Ricci et al., [18] reached a maximum power coefficient of $(25.1 \%)$ for the helical Savonius rotor by investigating the effect of end plates and overlap. Mohamed et al., [19] investigated the obstacle shielding effect on the performance of the Savonius rotor. The results showed that the highest increment in the output power was $75.4 \%$.

Coinciding with the development of the engineering software many studies were performed using the computational investigations on the Savonius rotor. Gupta et al., [20] numerically investigated the flow physics around the helical Savonius rotor. They found that the maximum power can be extracted when the rotor is positioned at $45^{\circ} \& 90^{\circ}$ with respect to the incoming flow. El-Baz et al., [21] introduced a new arranged design using multi-Savonius turbines. They concluded the novel triangular arrangement increased the power coefficient by about 44\%. Ghatage and Joshi [22] studied the effect of twist angle on the performance of the helical Savonius rotor. The optimal twist angle was $30^{\circ}$ and it can achieve a $C_{p}$ of 0.216 . Mohammadi et al., [23] investigated the effect of the nozzles on the performance of the Savonius rotor. They reported that the extracted power was three times more than the rotor without a nozzle. Al-Ghriybah et al., [24] studied the effect of inner blade position on the performance of the conventional rotor. They found that the maximum $\mathrm{Cp}$ can be generated when the inner blade tip is parallel with rotor tip.

Numerous numerical methods can be used in the computational fluid dynamics (CFD) studies. One of the most popular methods in analyzing the performance of the Savonius rotors is the finite volume method (FVM) using the ANSYS-Fluent software. In order to study the turbulent flow around 
the Savonius rotor, there are different models to solve turbulent flow. However, research done by Larin et al., [25] suggested that the realizable k-e model was the most accurate in determining the performance of the Savonius rotor.

While there are various powerful techniques to harvest wind energy, many studies are attempting to improve the performance of the Savonius wind rotor in terms of $C_{p}$ by optimizing the shape of blades or adding power augmentations like windshields. The design of the Savonius wind rotor needs to be the focus of development in order to improve the generated torque by the rotor. Consequently, there should be a study on the Savonius rotor in relation to the addition of inner blades in order to improve the performance of the rotor.

Most of the previous studies on the Savonius rotor were performed to enhance the performance of the rotor using the main design parameter. In this paper, the performance of the Savonius rotor with external overlap and two inner blades at a low tip speed ratio (TSR) will be investigated and compared to the conventional rotor. Moreover, the spacing between the blades will be investigated in order to determine the optimum value of the spacing. The addition of the inner blades on the main blade is expected to enhance the power performance of the rotor. The study has been performed with the assist of numerical simulations using the software (ANSYS fluent 19.2).

\section{Design and Numerical Methods}

Savonius rotor performance can be accurately predicted utilizing the 2-D simulation. Usually, the flow in the vertical axis is neglected since the rotor configuration is symmetric along with the turbine height. Thus, neglecting the axial vertical flow will be equivalent to the 3-D simulation of the rotor with end plates [26].

\subsection{Configuration Design}

The new configuration of the Savonius rotor consists of two main blades with two inner blades as shown in Figure 1. The dimensions of the blades are illustrated in Table 1, where 0 is the shaft diameter, D1 is the main blade diameter, D2 and D3 are the diameters of the inner blades, e1 is the distance between blade 1 and blade 2, and e2 is the distance between blade 2 and blade 3 . Three values of spacing were adopted between the blades $(0.02,0.01$, and $0.005 \mathrm{~m})$. The thickness of all blades was $0.002 \mathrm{~m}$, and the overlap between the main blade (blade 1) and the shaft was $0.018 \mathrm{~m}$.

Table 1

Dimensions of the new configuration

\begin{tabular}{ll}
\hline Parameter & Value \\
\hline O & $0.03 \mathrm{~m}$ \\
D1 & $0.188 \mathrm{~m}$ \\
D2 & $0.144 \mathrm{~m}$ \\
D3 & $0.100 \mathrm{~m}$ \\
e1 & $0.02 \mathrm{~m}, 0.01 \mathrm{~m}, 0.005 \mathrm{~m}$ \\
e2 & $0.02 \mathrm{~m}, 0.01 \mathrm{~m}, 0.005 \mathrm{~m}$ \\
\hline
\end{tabular}




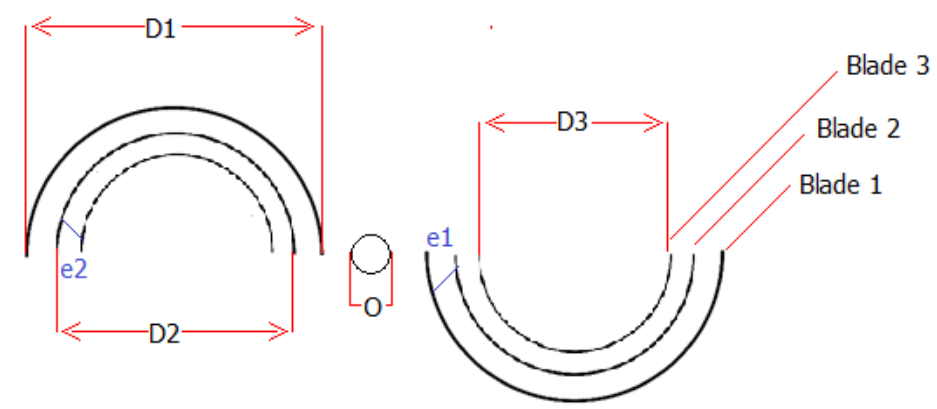

Fig. 1. New configuration of Savonius rotor with inner two blades

\subsection{Performance Coefficients}

For performance comparison, coefficient of torque calculated from the aerodynamic forces generated on both blades of the rotor was monitored in ANSYS-Fluent. Since the main objective of this study was to determine the maximum generated power using the configuration of two inner blades at specific TSR, the coefficient of power $\left(C_{p}\right)$ and coefficient of torque $\left(C_{t}\right)$ can be defined as:

$C_{p}=C_{t} \times T S R$

$C_{t}=\frac{4 T}{\rho U^{2} D^{2} H}$

The total generated torque from the Savonius turbine $(T)$ can be calculated using Eq. (3) by integrating the total forces resulting from both pressure $\left(F_{f}^{\text {pressure }}\right)$ and shear force $\left(F_{f}^{\text {shear }}\right)[23,27]$.

$$
\begin{aligned}
T & =\sum_{f}\left(F_{f}^{\text {pressure }}+F_{f}^{\text {shear }}\right) \cdot L \\
& =\sum_{f}\left(\left[\left(P_{f}-P_{\text {ref }}\right) A_{f}+\left(-\tau_{f} \cdot A_{f}\right)\right]_{\text {concave }}-\left[\left(P_{f}-P_{\text {ref }}\right) A_{f}+\left(-\tau_{f} \cdot A_{f}\right)\right]_{\text {convex }}\right) \cdot L
\end{aligned}
$$

Where $P_{f}$ is the static pressure, $P_{r e f}$ is the reference pressure, $A_{f}$ is the projected area of the turbine, and $L$ is the torque arm length.

\subsection{Numerical Method}

Two-dimensional CFD simulation was adopted in this study using the ANSYS fluent 19.2 software. The meshing was accomplished using ANSYS-meshing package. Models of the rotor were drawn using AutoCAD 2016. The Navier-Stokes equations were used to describe the dynamics of the incompressible Newtonian fluid flow. ANSYS Fluent is utilized in order to solve these equations with a second-order numerical model. The $\mathrm{K}-\varepsilon /$ realizable turbulence model was adopted depending on the previous studies in the same area [24].

The computational domain was set according to the previous study [19] where the computational domain is in a shape of square domain as shown in Figure 2 . The domain has to be suitable in a way that it does not affect the results, for that a domain with size $(L \times L)$ where $L=20$ times the rotor radius is suitable for the CFD simulation. The circular region in the domain (where the blades are placed) is set to be a moving region, whereas the square region is set to be a fixed region where it represents the wind tunnel. The inlet was defined as velocity inlet with wind velocity $(U=9 \mathrm{~m} / \mathrm{s})$ and the outlet was set as pressure outlet. 
A grid independence test has been conducted for the conventional rotor. Several grids were adopted in the 2-D simulation with different qualities. Meshes composed of $32,000-150,000$ cells have been tested for the turbine. All used grids with more than 95,000 cells lead to a relative variation of the output quantity below than $0.9 \%$. Since the cost of the CFD evaluation clearly increases rapidly with the number of cells in the mesh, the medium mesh with a cell ranges between 89,000 and 100,000 has been adopted for all further results shown in this paper.

The generated mesh in both computational zones (rectangular stationary zone and circular moving zone) can be found in Figure 3. The minimum grid size utilized was $2.5 \mathrm{~mm}$ at the moving zone, and the largest size was $107 \mathrm{~mm}$ at the stationary zone. Inflation was applied to the walls of the rotor with 25 layers, $0.05 \mathrm{~mm}$ first layer high, and 1.1 growth rates.

A validation study was also conducted to the experimental study proposed by Driss et al., [28] in order to validate the numerical simulation procedure.

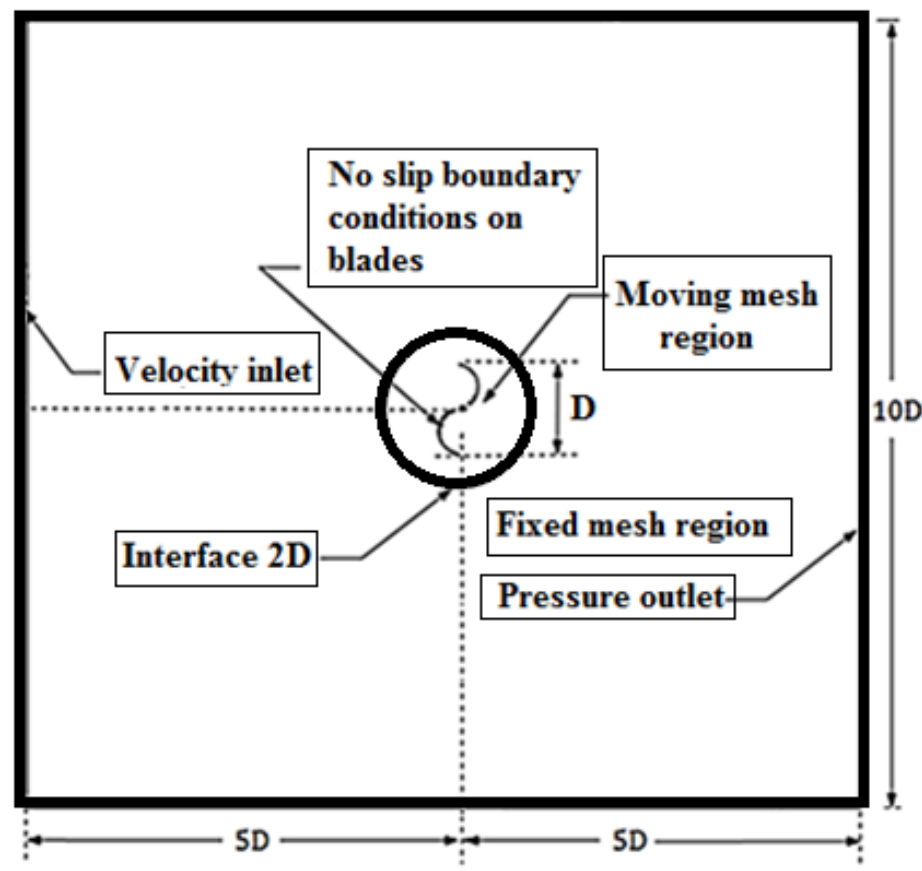

Fig. 2. Computational domain

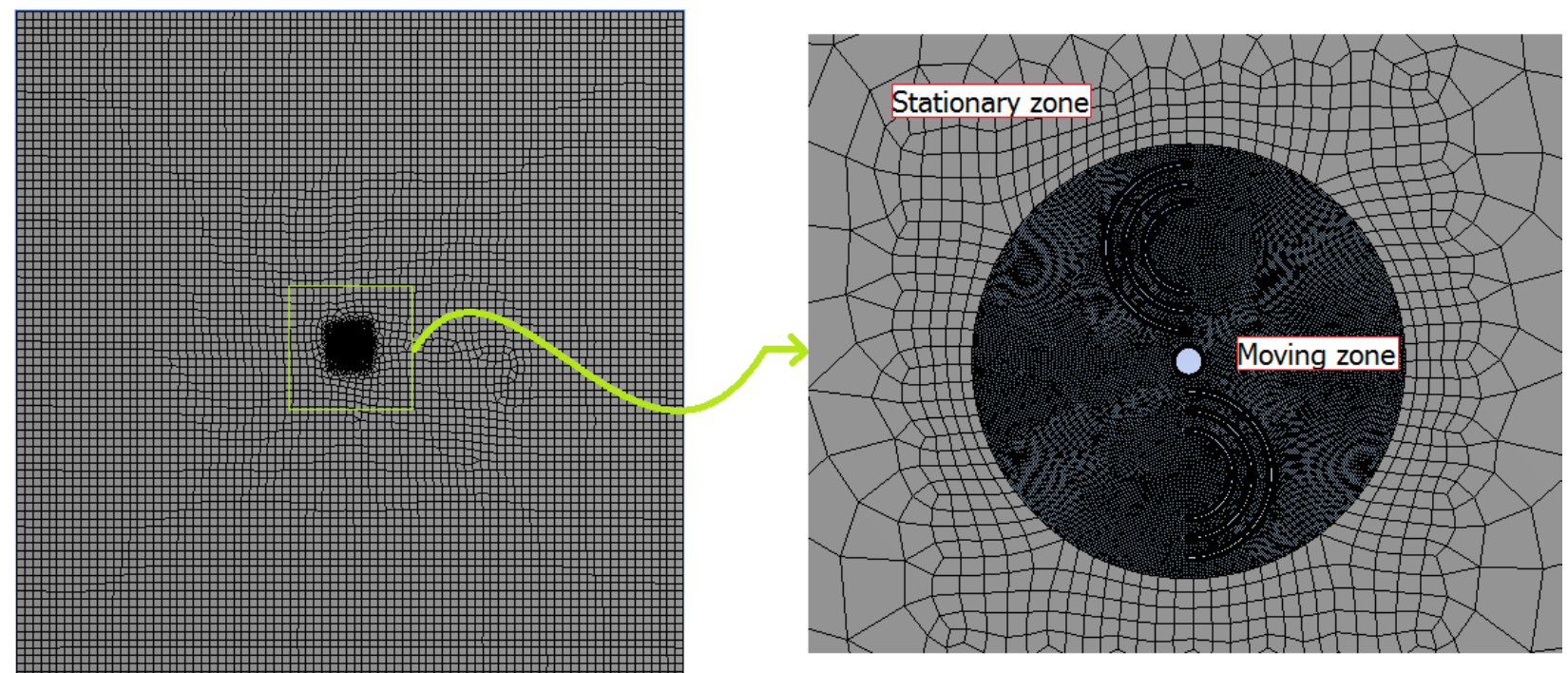

Fig. 3. Generated mesh in computational zones 


\section{Results and Discussion}

The 2-D simulation results showed a good agreement with the published experimental results by Driess et al., [28]. Figure 4 shows the results in terms of Cp at three tested TSRs. It observed that the maximum error was $8.6 \%$ between the simulation and experimental results which gives the reliability for the 2-D simulation.

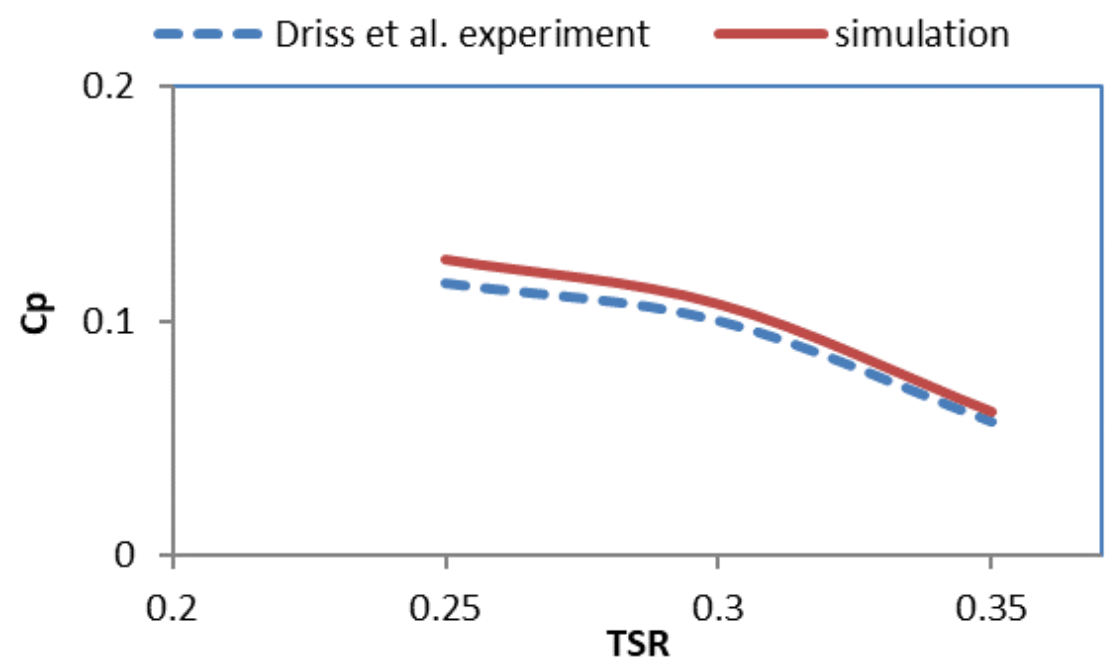

Fig. 4. Validation results

\subsection{Conventional Rotor Vs. Two-inner Blade Rotor}

The new configuration and the conventional Savonius rotor were simulated at low TSR values $(0.2,0.25,0.30,0.35$, and 0.40$)$. Figure 5 shows a plot of $C_{t} v s$. TSR for both rotors. In terms of $C_{t}$, it can be clearly noticed that the turbine's static torque enhances with the increase of the TSR after adding the two inner blades in a completely opposite way to the conventional rotor where the torque coefficient decreases with the increment of the TSR values. $C_{t}$ values for the new configuration are higher than the conventional rotor when the TSRs were $0.30,0.35$, and 0.40 , whereas at TSR $=0.2$ and 0.25 the conventional rotor performs better in terms of torque. Figure 6 demonstrates a plot between $C_{p}$ and TSR values for the same two rotors. It is also can be observed that the new configuration has a higher power performance than the conventional rotor expects at the lowest considered TSRs of 0.20 and 0.25 . At higher TSRs of $0.30,0.35$, and 0.40 , performance improves by $3 \%, 10.3 \%$, and $17.1 \%$, respectively, when comparing to the conventional rotor. For the new configuration, the maximum $C_{p}$ occurs at TSR $=0.4$ with a value of 0.188 and the minimum is noted at TSR $=0.2$ with a value of 0.077 . Figure 7 illustrates a plot of the instantaneous $C_{t}$ vs. azimuth position of the blade $(\theta)$ for the rotor with and without inner blades at TSR of 0.4 where the maximum power occurred. From this plot, it can be observed that the peak value of $C_{t}$ is approximately doubled when comparing the rotor with and without inner blades. An enhancement in the turbine's efficiency is attributable to an increment in the values of the average $C_{t}$ over a complete rotation. Although the conventional rotor has larger $C_{t}$ at rotor angles $\left(0^{\circ}-60^{\circ}\right)$ and $\left(150^{\circ}-240^{\circ}\right)$ than the new rotor configuration, $C_{t}$ values of the new configuration is greater for all the other rotor angles, this can be clearly noticed on the values of the average $C_{t}$ where it was 0.4 for the conventional rotor and 0.47 for the rotor with inner blades. Moreover, the maximum torque is generated when the blade was in a position of $85^{\circ}$ for the rotor without inner blades and $120^{\circ}$ with inner blades. It is also worth to mention that the values of the $C_{t}$ were positive for all the tested TSRs for both rotors. 
The difference in pressure between the concave and convex sides of the blades generates a torque that forces the turbine to start the rotation. Thus, large pressure difference means larger torque and hence, will increase the generated power. To more detailed reasons for the enhancement of the rotor performance, a comparison in terms of pressure and velocity contours of the rotor with and without inner blades at TSR of 0.4 and rotor position of $120^{\circ}$ is illustrated in figure 8 and Figure 9. At this azimuth angle, the $C_{t}$ instantaneous values were 0.37 for the rotor without inner blades and 0.62 for the rotor with inner blades. It can be clearly seen from Figure 8 that the pressure on the concave side increases after adding the inner blades. Although the negative torque on the convex side also increases, the net pressure difference is much higher than the conventional rotor without inner blades.

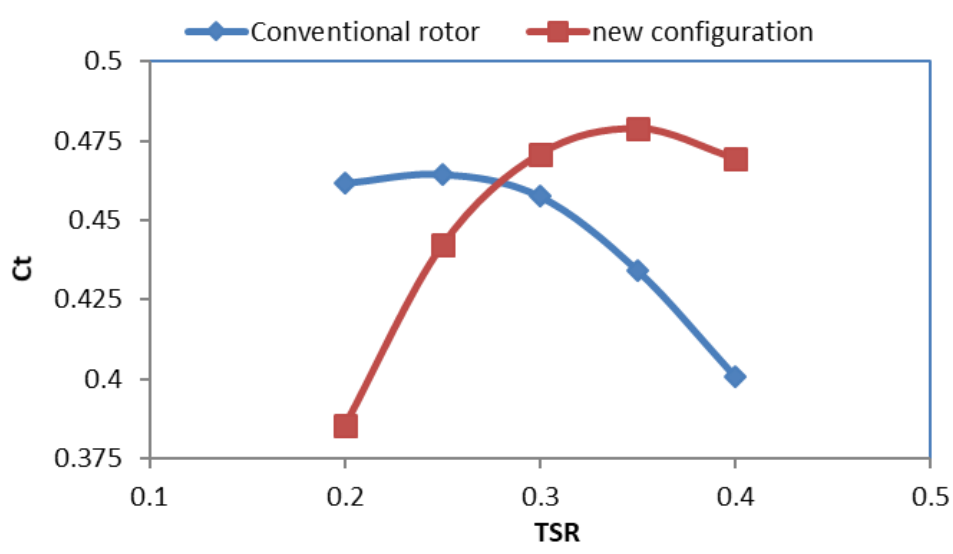

Fig. 5. Variations of Torque Coefficient with Respect to TSR

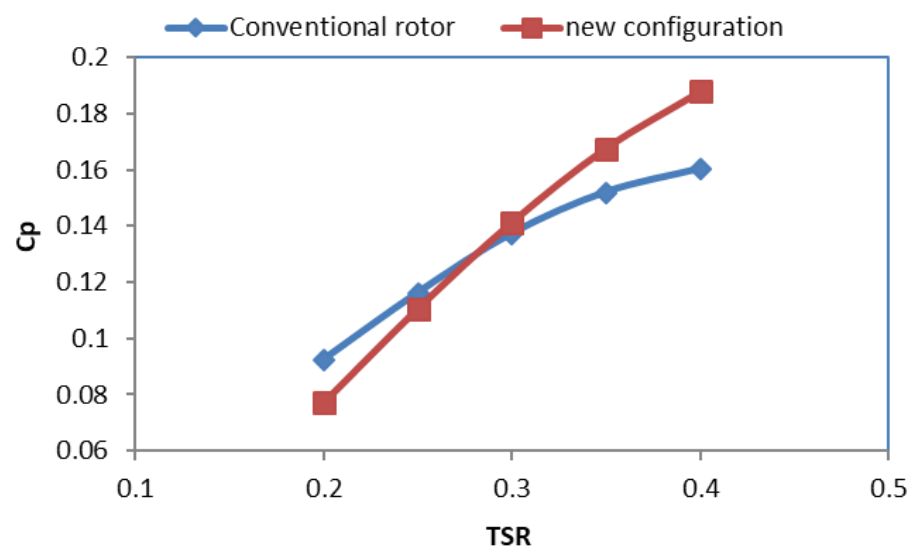

Fig. 6. Variations of Power Coefficient with Respect to TSR

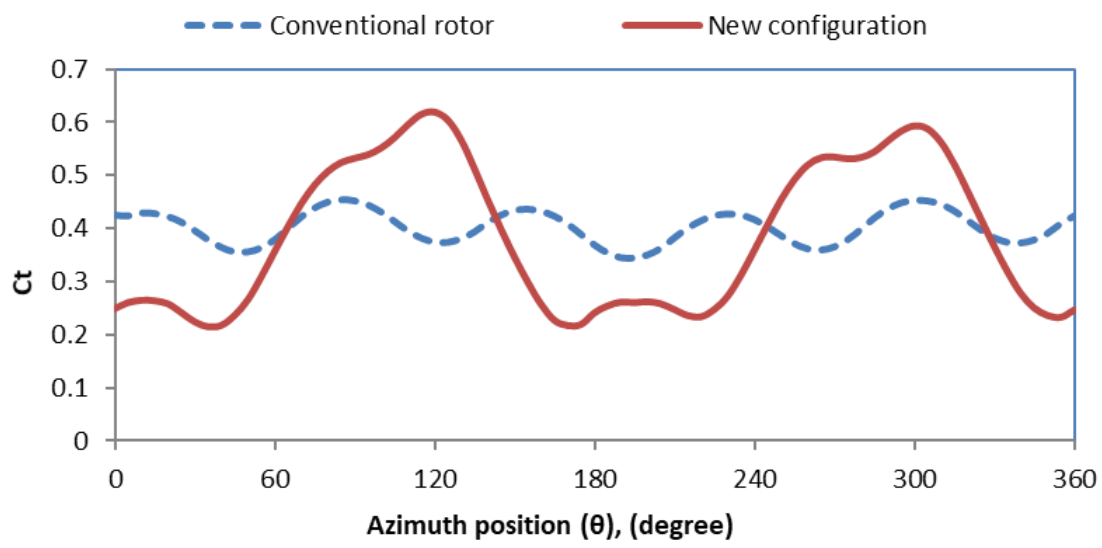

Fig. 7. $C_{t}$ vs. $\theta$ at TSR $=0.4$ 

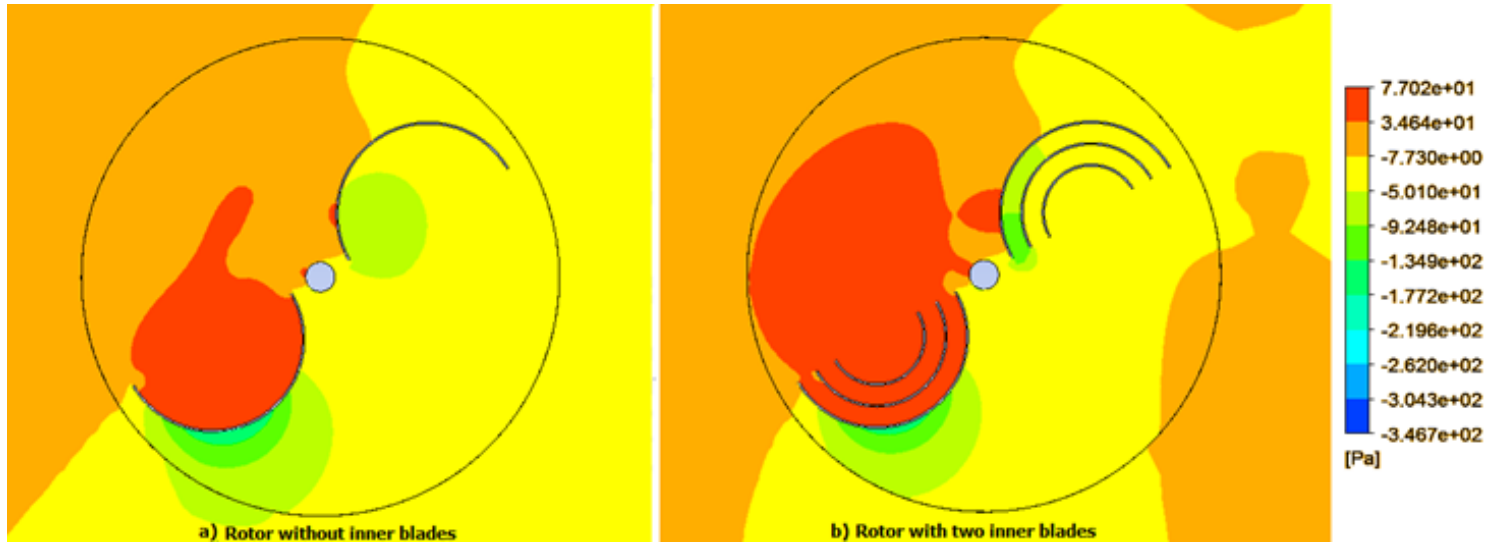

Fig. 8. Pressure contours comparison for the (a) rotor without inner blades and (b) rotor with two inner blades

In addition to the pressure contours which explained the increase in torque values, Figure 9 illustrates the velocity contours for the same configurations and at same TSR. In the case of using inner blades, it is obvious that the flow around the rotor becomes a little bit complex. Generally, high wind velocity means a low-pressure area. Higher wind speeds which generated on the tip of the advancing blade will cause a pressure reduction on the convex side of the moving blade.
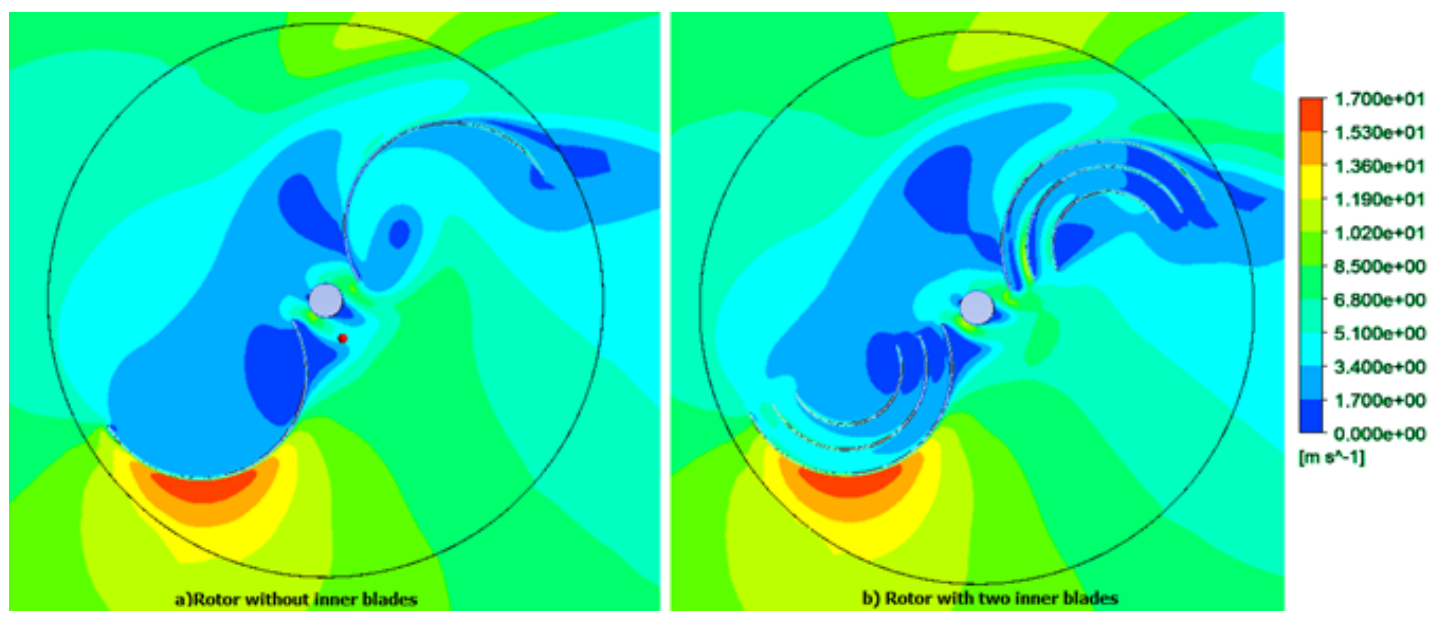

Fig. 9. Velocity contours comparison for the (a) rotor without inner blades and (b) rotor with two inner blades

\subsection{Effect of Inner Blades Spacing}

Three values of spacing $(0.02,0.01$, and $0.005 \mathrm{~m})$ between the inner blades were simulated using CFD ANSYS software. The main spacing was $0.02 \mathrm{~m}$ which used in section 3.1 where e1 $=\mathrm{e} 2$. As the main configuration with the same boundary conditions five values of TSR were used to conduct the simulation. Average $C_{t}$ for the three rotors is plotted and compared versus TSR as illustrated in Figure 10. It is clear that the rotor with more space between its inner blades generates more torque where $C_{t}$ values decrease by reducing the spacing between the inner blades. Figure 11 shows the performance of the rotors in terms of $C_{p}$ Vs. TSR. It can be seen that the rotor with $0.02 \mathrm{~m}$ spacing has the maximum $C_{p}$. On the other hand, reduction in $C_{p}$ can be noted when the space between the blades increased. Moreover, the reduction in the performance wasn't high where the reduction was $2.6 \%$ for the rotor with e1 = e2 $=0.005 \mathrm{~m}$, and $4.2 \%$ for e $1=\mathrm{e} 2=0.01 \mathrm{~m}$ comparing with the main 
configuration with e1 $=\mathrm{e} 2=0.02$. The decrease in $C_{p}$ values is due to the reduction of the amounts of trapped air between the inner blades which reduces the generated pressure on the rotor blades.

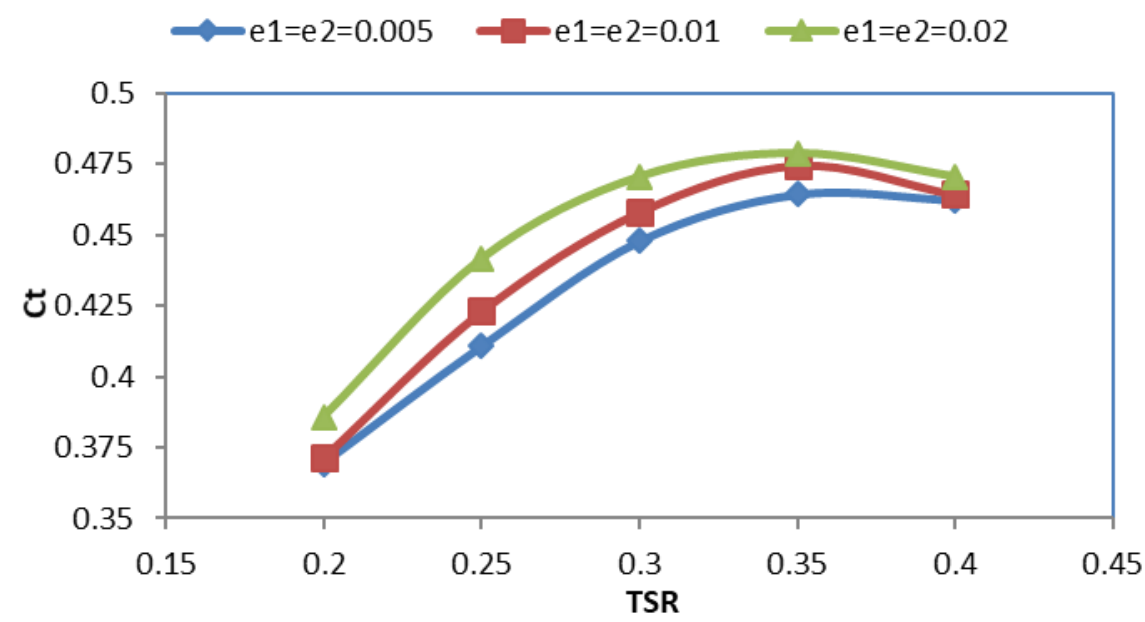

Fig. 10. Variations of Torque Coefficient with Respect to TSR with different blade spacing

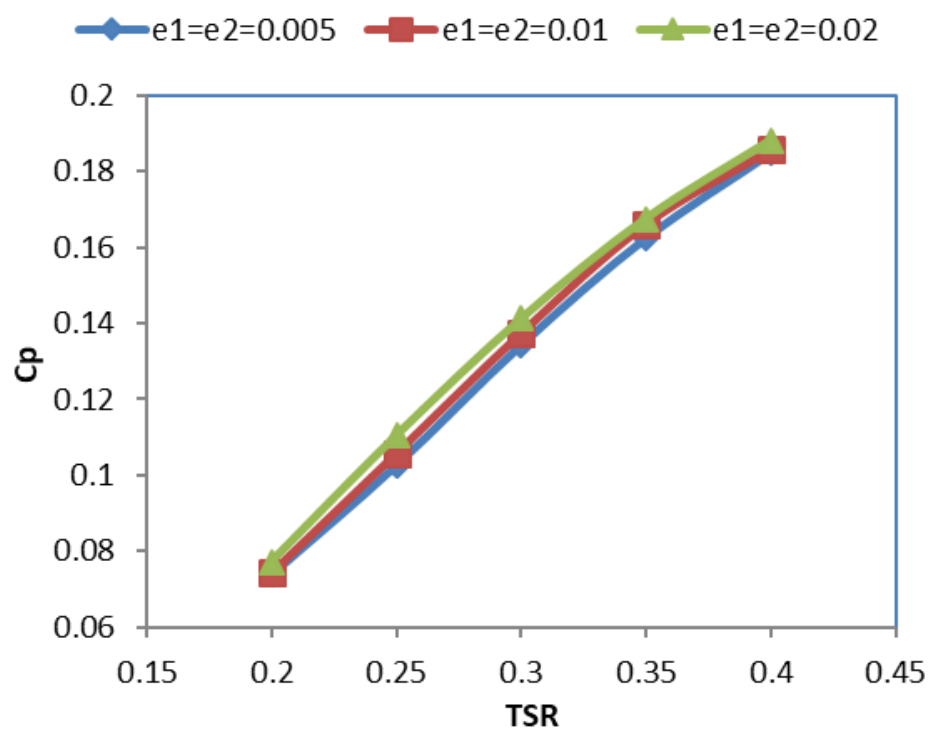

Fig. 11. Variations of power Coefficient with Respect to TSR with different blade spacing

\section{Conclusions}

Savonius rotor with and without inner blades was successfully simulated at five different values of TSR. Additionally, the effect of space between the inner blades was investigated. The simulation was in 2-D and it was done with the assist of ANSYS software 19.2. The key findings can be summarized as follows:

i. Savonius rotor with two inner blades generates more torque compared to the conventional rotor expect at the lowest considered TSRs of 0.2 and 0.25 .

ii. The heights $\mathrm{Cp}$ improvement was for the rotor with two inner blades at TSR $=0.4$ with a percentage of $17.1 \%$ and a value of 0.188 ; this improvement was due to the high generated pressure on the advancing blade. 
iii. Addition of inner blades causes a shift in the azimuth position for the peak $\mathrm{Ct}$ value from $85^{\circ}$ to $120^{\circ}$.

iv. A reduction in terms of power and torque was noticed when the space between the inner blades decreased.

Different values of space between each blade and the effect of the inner blade's profile could be as future work.

\section{Acknowledgement}

The authors would like to thank Ministry of Education Malaysia (MoE) and Universiti Tun Hussein Onn Malaysia for the publication funding and research facilities.

\section{References}

[1] Ji, Qiang, and Dayong Zhang. "How much does financial development contribute to renewable energy growth and upgrading of energy structure in China?." Energy Policy 128 (2019): 114-124.

https://doi.org/10.1016/i.enpol.2018.12.047

[2] Herbert, GM Joselin, Selvaraj Iniyan, E. Sreevalsan, and S. Rajapandian. "A review of wind energy technologies." Renewable and Sustainable Energy Reviews 11, no. 6 (2007): 1117-1145.

https://doi.org/10.1016/i.rser.2005.08.004

[3] Sun, Xiaojing, Yingqiao Xu, and Diangui Huang. "Numerical simulation and research on improving aerodynamic performance of vertical axis wind turbine by co-flow jet." Journal of Renewable and Sustainable Energy 11, no. 1 (2019): 013303. https://doi.org/10.1063/1.5052378

[4] Didane, Djamal Hissein, Nurhayati Rosly, Mohd Fadhli Zulkafli, and Syariful Syafiq Shamsudin. "Numerical investigation of a novel contra-rotating vertical axis wind turbine." Sustainable Energy Technologies and Assessments 31 (2019): 43-53.

https://doi.org/10.1016/i.seta.2018.11.006

[5] Al-Ghriybah, Mohanad, Hüseyin Çamur, Mohd Fadhli Zulkafli, Muhammad Abid Khan, Youssef Kassem, and Engin Esenel. "Study of Multiple Half Blades Effect on the Performance of Savonius Rotor: Experimental Study and Artificial Neural Network (ANN) Model." Indian Journal of Science and Technology 11 (2018): 1-12. https://doi.org/10.17485/ijst/2018/v11i38/129966

[6] Bhutta, Muhammad Mahmood Aslam, Nasir Hayat, Ahmed Uzair Farooq, Zain Ali, Sh Rehan Jamil, and Zahid Hussain. "Vertical axis wind turbine-A review of various configurations and design techniques." Renewable and Sustainable Energy Reviews 16, no. 4 (2012): 1926-1939.

https://doi.org/10.1016/i.rser.2011.12.004

[7] Sharma, Sonu, and Rajesh Kumar Sharma. "Performance improvement of Savonius rotor using multiple quarter blades-A CFD investigation." Energy Conversion and Management 127 (2016): 43-54. https://doi.org/10.1016/j.enconman.2016.08.087

[8] Hadi, Syamsul, Hasnul Khuluqi, Dandun Mahesa Prabowoputra, Ari Prasetyo, D. D. D. P. Tjahjana, and Ahmad Farkhan. "Performance of Savonius Horizontal Axis Water Turbine in Free Flow Vertical Pipe as Effect of Blade Overlap." Journal of Advanced Research in Fluid Mechanics and Thermal Sciences 58, no. 2 (2019): 219-223.

[9] Islam, M. R., S. Mekhilef, and R. Saidur. "Progress and recent trends of wind energy technology." Renewable and Sustainable Energy Reviews 21 (2013): 456-468. https://doi.org/10.1016/j.rser.2013.01.007

[10] Didane, Djamal Hissein, Nurhayati Rosly, Mohd Fadhli Zulkafli, and Syariful Syafiq Shamsudin. "Performance evaluation of a novel vertical axis wind turbine with coaxial contra-rotating concept." Renewable Energy 115 (2018): 353-361.

https://doi.org/10.1016/i.renene.2017.08.070

[11] Al-Ghriybah, Mohanad, Mohd Fadhli Zulkafli, Djamal Hissein Didane, and Sofian Mohd. "Review of the Recent Power Augmentation Techniques for the Savonius Wind Turbines." Journal of Advanced Research in Fluid Mechanics and Thermal Sciences 60, no. 1 (2019): 71-84.

[12] Bhuyan, S., and A. Biswas. "Investigations on self-starting and performance characteristics of simple $\mathrm{H}$ and hybrid H-Savonius vertical axis wind rotors." Energy Conversion and Management 87 (2014): 859-867. https://doi.org/10.1016/j.enconman.2014.07.056 
[13] Tian, Wenlong, Zhaoyong Mao, Baoshou Zhang, and Yanjun Li. "Shape optimization of a Savonius wind rotor with different convex and concave sides." Renewable Energy 117 (2018): 287-299. https://doi.org/10.1016/j.renene.2017.10.067

[14] Mahmoud, N. H., A. A. El-Haroun, E. Wahba, and M. H. Nasef. "An experimental study on improvement of Savonius rotor performance." Alexandria Engineering Journal 51, no. 1 (2012): 19-25. https://doi.org/10.1016/j.aej.2012.07.003

[15] Bhayo, B. A., H. H. Al-Kayiem, and N. Z. Yahaya. "Performance investigation of the S-Rotors." In IOP Conference Series: Materials Science and Engineering, vol. 100, no. 1, p. 012043. IOP Publishing, 2015. https://doi.org/10.1088/1757-899X/100/1/012043

[16] Roy, Sukanta, and Ujjwal K. Saha. "Wind tunnel experiments of a newly developed two-bladed Savonius-style wind turbine." Applied Energy 137 (2015): 117-125. https://doi.org/10.1016/i.apenergy.2014.10.022

[17] Kamoji, M. A., S. B. Kedare, and S. V. Prabhu. "Performance tests on helical Savonius rotors." Renewable Energy 34, no. 3 (2009): 521-529. https://doi.org/10.1016/i.renene.2008.06.002

[18] Ricci, Renato, Roberto Romagnoli, Sergio Montelpare, and Daniele Vitali. "Experimental study on a Savonius wind rotor for street lighting systems." Applied Energy 161 (2016): 143-152. https://doi.org/10.1016/j.apenergy.2015.10.012

[19] Mohamed, M. H., G. Janiga, E. Pap, and D. Thévenin. "Optimal blade shape of a modified Savonius turbine using an obstacle shielding the returning blade." Energy Conversion and Management 52, no. 1 (2011): 236-242. https://doi.org/10.1016/j.enconman.2010.06.070

[20] Gupta, Rajat, Bachu Deb, and R. D. Misra. "Performance analysis of a helical Savonius rotor with shaft at 45 twist angle using CFD." Mechanical Engineering Research 3, no. 1 (2013): 118. https://doi.org/10.5539/mer.v3n1p118

[21] El-Baz, A. R., K. Youssef, and M. H. Mohamed. "Innovative improvement of a drag wind turbine performance." Renewable Energy 86 (2016): 89-98. https://doi.org/10.1016/i.renene.2015.07.102

[22] Ghatage, Swapnil V., and Jyeshtharaj B. Joshi. "Optimisation of vertical axis wind turbine: CFD simulations and experimental measurements." The Canadian Journal of Chemical Engineering 90, no. 5 (2012): 1186-1201. https://doi.org/10.1002/cjce.20617

[23] Mohammadi, M., R. Mohammadi, A. Ramadan, and M. H. Mohamed. "Numerical investigation of performance refinement of a drag wind rotor using flow augmentation and momentum exchange optimization." Energy 158 (2018): 592-606. https://doi.org/10.1016/j.energy.2018.06.072

[24] Al-Ghriybah, Mohanad, Mohd Fadhli Zulkafli, Djamal Hissein Didane, and Sofian Mohd. "The effect of inner blade position on the performance of the Savonius rotor." Sustainable Energy Technologies and Assessments 36 (2019): 100534. https://doi.org/10.1016/i.seta.2019.100534

[25] Larin, P., M. Paraschivoiu, and C. Aygun. "CFD based synergistic analysis of wind turbines for roof mounted integration." Journal of Wind Engineering and Industrial Aerodynamics 156 (2016): 1-13. https://doi.org/10.1016/j.jweia.2016.06.007

[26] Antar, E., and M. Elkhoury. "Parametric sizing optimization process of a casing for a Savonius Vertical Axis Wind Turbine." Renewable Energy 136 (2019): 127-138. https://doi.org/10.1016/j.renene.2018.12.092

[27] Nasef, M. H., W. A. El-Askary, A. A. Abdel-Hamid, and H. E. Gad. "Evaluation of Savonius rotor performance: Static and dynamic studies." Journal of Wind Engineering and Industrial Aerodynamics 123 (2013): 1-11. https://doi.org/10.1016/j.jweia.2013.09.009

[28] Driss, Zied, Ali Damak, and Mohamed Salah Abid. "Evaluation of the Savonius Wind Rotor Performance for Different External Overlap Ratios." International Journal of Fluid Mechanics \& Thermal Sciences 1, no. 1 (2015): 14-21. https://doi.org/10.11648/i.ijfmts.20150101.13 